\section{Fibrinogen-Funktion-turbidimetrischer Test}

T. Stief

Institut für Laboratoriumsmedizin und Pathobiochemie, Krankenhaus der Philipps-Universität, Marburg, Deutschland

\section{Synonym(e) FIFTA}

Englischer Begriff fibrinogen function turbidimetric assay

Definition $>$ Thrombin in physiologischer/pathophysiologischer Plasmaaktivität (ca. 0,1-0,2 IE/ml) wandelt Fibrinogen in Fibrin um. Das bei der Polymerisation eingebaute Albumin trübt das entstehende Gerinnsel. Diese Trübung wird z. B. bei $405 \mathrm{~nm}$ gemessen und ist ein direktes Maß für die funktionelle Fibrinogen-Konzentration in vivo im Plasma.

Beschreibung Physiologische oder pathophysiologische plasmatische Thrombinaktivitäten im gerinnenden fließenden Blut sind nicht höher als $1 \mathrm{IE} / \mathrm{mL}$. Sie liegen um die $0,1 \mathrm{IE}$ Thrombin pro $\mathrm{mL}$ Blut. Fibrinogen als das Zielmolekül von Thrombin sollte folglich nicht mit unphysiologisch hohen
Thrombinaktivitäten im Test konfrontiert werden; daneben sollte das Plasma nicht 10-fach verdünnt werden. Beides kann die In-vivo-Situation von plasmatischem Fibrinogen verzerrt reflektieren und zu artifiziellen (insbesondere falsch hohen) Ergebnissen führen. Der FIFTA misst im Gegensatz zu herkömmlichen Fibrinogen-Tests die Fibrinogen-Funktion in Anwesenheit von lediglich 0,2 IE Thrombin pro $\mathrm{mL}$ in Citratplasma, das lediglich 1+2 mit Thrombin-Albumin-PolybrenReagenz verdünnt wird. Jedes $>$ Photometer (insbesondere auch $>$ Mikrotiterplatten-Photometer) kann den Trübungsanstieg pro $2 \mathrm{~min}\left(37^{\circ} \mathrm{C}\right)$ messen. Spezielle Gerinnungsanalyzer sind nicht notwendig. Die Fibrinogen-Funktion wird (vergleichbar der AT3-Funktion) in \% der Norm angegeben $(100 \%=2,8 \mathrm{~g} / \mathrm{L})$. Der Normbereich ist $100 \pm 20 \%$ (Mittelwert $= \pm 1$ Standardabweichung).

\section{Literatur}

Stief TW (2008) The fibrinogen functional turbidimetric assay. Clin Appl Thromb Hemost 14:84-96

Stief TW, Ulbricht K, Max M (2010) Circulating plasmin activity in severe sepsis. Hemost Lab 3:105-120 